\title{
Aspectos Artísticos no Projeto de Design de Identidade Gráfico- Visual de Marca
}

Sarah Schmithausen Schmiegelow é Doutoranda no programa Pós-Design da Universidade Federal de Santa Catarina. Mestra em Engenharia e Gestão do Conhecimento - UFSC. Integrante do grupo de pesquisa Significação da Marca, Informação e Comunicação Organizacional (SIGMO/UFSC/CNPq).

< asarahschmiegelow@gmail.com> ORCID: 0000-0002-5282-8630

Richard Perassi Luiz de Sousa é Doutor em Comunicação e Semiótica - PUC/ SP. Professor titular da Universidade Federal de Santa Catarina, atua nos programas de pós-graduação em Design e Engenharia e Gestão do Conhecimento, e no programa de graduação em Design. Líder do grupo de pesquisa Significação da Marca, Informação e Comunicação Organizacional (SIGMO/UFSC/CNPq).

<richard.perassi@uol.com.br>

ORCID: 0000-0003-0696-4110
Resumo Atualmente, há dificuldades para se estabelecer distinções evidentes entre Design e Arte. Tradicionalmente e predominantemente, considera-se as atividades de Design pertinentes ao contexto tecnológico, porque conhecimentos científicos e recursos tecnológicos são sistematicamente aplicados em métodos e processos de projetação. Na Arte, tradicionalmente, a aplicação de recursos científicos e tecnológicos não é necessária, porque a diferença característica da produção artística decorre mais especificamente de processos estético-intuitivos. Apesar das áreas serem aqui percebidas como tradicionalmente distintas, são observáveis aspectos estético-intuitivos nos projetos de Design e aspectos lógico-tecnológicos nos processos artísticos. Neste artigo são evidenciados os aspectos estético-intuitivos ou artísticos no projeto de Design de identidade gráfico-visual de marca, especialmente na parte criativa de geração de alternativas. Para tanto, foi considerada a recorrência da parte criativa nas propostas metodológicas de Design, ressaltando-se os aspectos processuais qualitativos, analógicos e intuitivos, os quais permitem ou impõem decisões estéticas ou artísticas na projetação da identidade gráfico-visual de marca.

Palavras chave Design Gráfico, Arte, Tecnologia, Metodologia de Projeto, Identidade Gráfico-visual. 


\title{
Artistic aspects in the design of graphic-visual brand identity
}

\begin{abstract}
Currently, it is difficult to establish clear distinctions between Design and Art. Traditionally and predominantly, design activities are relevant to the technological context, because scientific knowledge and technological resources are systematically applied in design methods and processes. In Art, traditionally, the application of scientific and technological resources it is not necessary, because the differentiation of artistic production is in the aesthetic-intuitive processes. Although traditionally distinct, aesthetic-intuitive aspects are observed in Design and logical-technological aspects in the artistic processes. This article highlights the aesthetic-intuitive or artistic aspects in the design of graphic-visual brand identity, especially in the creative phase of alternatives generation. We considered the recurrence of the creative part in the Design methodologies, emphasizing the qualitative, analogical and intuitive aspects that allow or impose aesthetic or artistic decisions in the graphic-visual brand identity design.
\end{abstract}

Keywords Graphic Design, Art, Technology, Design Methodology, Graphic-visual Identity.

\section{Aspectos artísticos en el diseño de identidad gráfico-visual de marca}

Resumen Actualmente, es difícil establecer distinciones evidentes entre Diseño y Arte. Tradicionalmente y predominantemente, las actividades de diseño se consideran relevantes para el contexto tecnológico, porque el conocimiento científico $y$ los recursos tecnológicos se aplican sistemáticamente en métodos y procesos de diseño. En Arte, tradicionalmente, la aplicación de recursos científicos y tecnológicos no es necesaria, porque la diferencia característica de la producción artística proviene más específicamente de los procesos estético-intuitivos. Aunque las áreas se perciben aquí como tradicionalmente distintas, se observan aspectos estético-intuitivos en lo diseño y aspectos lógico-tecnológicos en los procesos artísticos. Este artículo destaca los aspectos estético-intuitivos o artísticos en el diseño de identidad gráfico-visual de marca, especialmente en la parte creativa de generación de alternativas. Para tal fin, se consideró la recurrencia de la parte creativa en las propuestas metodológicas de Diseño, enfatizando los aspectos procesales cualitativos, analógicos e intuitivos, que permiten o imponen decisiones estéticas o artísticas en el diseño de identidad gráfico-visual de marca.

Palabras clave Diseño Gráfico, Arte, Tecnología, Metodología de Diseño, Identidad Gráfico-visual. 


\section{Introdução}

Este artigo apresenta uma síntese de parte dos estudos sobre as relações contemporâneas entre Design, Arte, Ciência e Tecnologia. Sobre o conceito de "Tecnologia", os estudos que fundamentam este artigo foram baseados nas ideias de Mario Bunge (1969), especialmente como essas são apresentadas e interpretadas por Alberto Cupani (2004). Assim, considera-se que a produção tecnológica inclui técnica e arte, mas depende necessariamente da aplicação sistemática de conhecimentos científicos em suas atividades e produtos. Por isso, o campo tecnológico incorpora e diferencia-se das atividades técnicas ou poético-artísticas, nas quais a aplicação de conhecimento científico é opcional.

As considerações e as proposições sobre as áreas de Design e Artes apresentadas neste artigo são fundamentadas por Perassi (2015). Sobre as áreas e as atividades de Design, considera-se que o uso de métodos e a necessidade de aplicação do conhecimento lógico-matemático no desenvolvimento de projetos, historicamente, distinguiram as áreas de Design das áreas de Artes, principalmente depois da consolidação da Revolução Industrial no final do século XIX e começo do século XX. Contudo, na prática, a clara distinção entre essas áreas não é amplamente evidente, especialmente na atualidade.

No domínio da produção industrial, a necessidade de replicação em escala de produtos idênticos, em aparência e funcionalidade, obrigou que os projetos de Design adotassem rígidos padrões científicos, métricos e geométricos. Isso permitiu o projeto de modelos funcionais de produtos, que pudessem ser eficientemente replicados em série nas indústrias. Por sua vez, em algumas áreas de Artes, especialmente nas artes plásticas, o alto valor atribuído à constante originalidade e à produção de obras únicas, em algumas circunstâncias, tornou opcional ou simplesmente desnecessária a adoção de métodos rígidos ou métricas deterministas.

A criatividade e a inovação também são valores básicos nas áreas de Design, visto que se espera que haja projetos criativos na proposição de novos modelos. Mas, as réplicas decorrentes do modelo inovador, via de regra, devem ser idênticas em aparência e funcionalidade. Portanto, tradicionalmente, um modelo projetado em Design deve atuar como uma "máquina conceitual", permitindo com exatidão a reprodução de produtos. Considera-se aqui que "Tecnologia" é o campo no qual é estudada e realizada a produção de máquinas mecânicas, eletrônicas, digitais ou conceituais, como sistemas de reprodução. Por isso as áreas de Design são situadas no campo tecnológico.

Anteriormente, a aplicação da ciência Matemática nos projetos de Design, especialmente através de Desenho Geométrico, era realizada diretamente pelos designers. Portanto, além da adoção de uma metodologia de Design e da realização de esboços "a mão livre", também era necessária a realização de cálculos geométricos no desenvolvimento do projeto. Mas, o processo intuitivo, realizado por "tentativa e erro", era e ainda é predominante na etapa criativa, com a proposição de alternativas estético-simbólicas e funcionais para o desenvolvimento do projeto. 
Atualmente, entretanto, além da necessidade de amplo reconhecimento do contexto sociocultural e mercadológico para o desenvolvimento de projetos, o processo criativo e a proposição de alternativas compõem a principal tarefa do processo projetivo. A ênfase na criatividade decorre do avanço da tecnologia digital na área de Computação Gráfica. A tarefa de metrificação tornou-se secundária, porque os programas digitais de desenho, automaticamente, metrificam os arranjos gráficos, apresentando-os como vetores de representações planas ou tridimensionais. Assim, vetorizados, os desenhos e as imagens em geral podem ser ampliados ou reduzidos em diversas escalas, sendo ainda automaticamente reproduzidos por diferentes impressoras eletromecânico-digitais.

$\mathrm{O}$ atual domínio da livre ação intuitivo-criativa que, pelo menos parcialmente, é realizada pelo processo de "tentativa e erro", tornou similar e praticamente indistintas parte dos procedimentos das áreas de Design e Artes. Os designers estão libertos da obrigação de realizar os cálculos geométricos, porque a razoabilidade lógico-matemática e a reprodutibilidade do modelo projetado são autonomamente garantidas pelo sistema tecnológico-digital. Por isso, podem exercer a livre criatividade que, tradicionalmente, caracterizou algumas áreas de Artes, sendo também o aspecto mais valorizado nas obras de arte em geral.

Este artigo tem como objetivo evidenciar os aspectos estético-intuitivos ou artísticos no projeto de Design de identidade gráfico-visual de marca, que estão presentes especialmente na etapa criativa de geração de alternativas. Trata-se de uma pesquisa descritiva de base qualitativa, pois são feitas observações, registros, correlações e descrições de fenômenos, mas, sem interferir na realidade estudada (VALENTIM, 2005). Foram realizados também estudos exploratórios, realizados para a seleção de fontes teóricas e figuras. Também, houve estudos teórico-bibliográficos e apresentação de figuras pré-selecionadas, como objetos visuais componentes da realidade estudada.

\section{Arte, Ciência, Técnica e Tecnologia}

De modo geral, Perassi (2005) propõe que as atividades artísticas e seus produtos respondem por toda produção material no campo da cultura. Trata-se aqui da replicação de uma distinção feita por Aristóteles, na Antiguidade Clássica, designando a Ciência como campo do conhecimento teórico ou conceitual, sendo que a Arte e a Natureza são os campos da produção material. Contudo, a Natureza produz as coisas mesmas, naturais, enquanto as atividades artísticas produzem as outras coisas, que são objetos e utensílios culturais. Em síntese, a produção cultural compõe o acervo artificial das coisas físicas ou materiais, as quais não são diretamente fornecidas pela natureza.

Conforme Japiassu e Marcondes (2001), de maneira também geral, a palavra "Arte" é proposta como designação de um conjunto de procedimentos para obtenção de um resultado prático, diferenciando-se de Ciência 
e Natureza. Inclusive, é assinalado que, em sentido prático, Arte é sinônima de Técnica. Mas, com relação às expressões "Arte Poética" e "Belas Artes", o sentido "poético" é considerado parte de sua caracterização, propondo neste caso a distinção entre Arte Poética e Técnica (JAPIASSU; MARCONDES, 2001; PERASSI, 2005).

As atividades técnicas não requerem necessariamente o investimento poético-intuitivo. Por exemplo, um bom resultado técnico pode ser obtido por uma máquina bem ajustada. Contudo, os conceitos de Arte e Técnica permanecem relacionados na medida em que as atividades artísticas, mesmo as mais poéticas, informais e vanguardistas, requerem procedimentos técnicos, sejam simples ou complexos.

Considerando-se que Arte poética é um conceito mais amplo e complexo que o designado pela palavra Técnica, seu desenvolvimento requer o uso refinado dos sentidos e de ilações lógico-objetivas ou intuitivo-subjetivas, incluindo associações muito sutis ou mesmo inconscientes. Tradicionalmente, o campo de Belas Artes é privilegiado no exercício dos processos estético-intuitivos, porque são exploradas as livres associações entre sensações e percepções cotidianas, sentimentos e intuições estético-subjetivas. As revoluções estéticas e conceituais propostas nas obras de arte de vanguarda, ou nas experiências estéticas decorrentes do acesso a obras de arte tradicionais, são ocasionadas por exercícios estético-intuitivos de qualidade, realizados pelos artistas e também pelos expectadores.

A expressividade estética ou os arranjos conceituais inovadores das obras de arte provocam os expectadores em geral, suscitando-lhes percepções e afetando-os de modos diferenciados que, inclusive, propõem novos conhecimentos. Contudo, na tradição modernista, a partir de meados do século XIX, o fazer poético-artístico foi sistematicamente percebido de maneira distinta das artes mecânicas e aplicadas, especialmente por não ser finalista. Em princípio, de modo diferenciado das atividades técnicas, tecnológicas, científicas ou religiosas, as proposições decorrentes de Arte poética não pretendem uma finalidade, como serem úteis ou verdadeiras (PERASSI, 2005).

Por sua vez, Ciência é um campo de conhecimento independente da aplicação prática, mesmo sendo finalista ao buscar conhecimentos verdadeiros (JAPIASSU; MARCONDES, 2001; PERASSI, 2005). Além disso, os cientistas também acreditam que os conhecimentos teórico-científicos podem fundamentar e orientar as experiências que buscam soluções práticas eficientes. Em síntese, a palavra "Ciência" designa o campo de sistematização de conhecimentos teóricos, como conjuntos conceituais decorrentes do entrosamento lógico de proposições verdadeiras sobre os fenômenos observados ou estudados (JAPIASSU; MARCONDES, 2001).

O conceito de tecnologia, por sua vez, é relacionado aos termos Técnica e Ciência, na perspectiva analítica de Mario Bunge, como é considerada por Cupani (2004). Assim como nas atividades técnicas, no desenvolvimento tecnológico o objetivo também é a produção de um "artefato", como algo artificial. Um artefato pode ser uma coisa material ou conceitual, como o 
modelo teórico para a realização de um processo ou o plano de modificação de um sistema natural.

Nos campos da técnica e da tecnologia, a criação e a produção de um artefato requerem uma finalidade e uma planificação ou projeto. Portanto, de modo geral e inicial, o artefato é primeiramente idealizado, porque assim é possível considerar e reunir de maneira sistemática os recursos necessários para produzi-lo. 0 objeto artificial resultante deve ser eficaz, por isso, necessita de uma finalidade prevista e de regras para sua produção, permitindo avaliar sua eficiência e economia.

As atividades técnicas buscam o controle empírico ou a transformação da natureza sem que, necessariamente, haja a aplicação sistemática do conhecimento científico. Assim, na técnica, o conhecimento científico pode ser aplicado, mas não é obrigatório, podendo ocorrer de maneira eventual ou assistemática. Portanto, concordando com os autores estudados (BUNGE, 1969; CUPANI, 2004), as atividades tecnológicas são diferenciadas das técnicas devido à aplicação obrigatória e sistemática do conhecimento científico.

\section{Design como campo tecnológico}

A palavra "forma" representa o princípio que determina uma porção de substância física ou matéria (JAPIASSU; MARCONDES, 2001). A forma é a ideia simplesmente sentida (estética) ou nominada (semântica) que identifica um arranjo físico ou material, como um conjunto de sensações específicas. Por isso, a forma diferencia os diversos arranjos compostos com o mesmo material. Por exemplo, é possível produzir pratos, canecas e potes com o mesmo barro cerâmico. Contudo, o barro é informado de maneira diferenciada em cada produto, provocando nos observadores conjuntos de sensações diferentes e, em suas mentes, promovendo ideias ou formas específicas.

Flusser (2007) descreve a interação entre forma (ideia) e matéria privilegiando a forma como elemento típico da mente e da cultura, que tende a ser mais perene que a matéria. Com base nisso, é assinalado que o cerne das atividades de Design é informar substâncias e materiais, para que esses expressem formas ou ideias e possam cumprir ou participar do cumprimento de funções específicas. Complementando, é possível dizer que, tradicionalmente e prioritariamente, as atividades de Design informam substâncias diversas, para compor projetos e modelos de produtos ou conjuntos de produtos.

Em seu estado mental, as formas ou as ideias não atuam ou interferem diretamente no mundo físico. Para terem efeito ideológico e prático neste mundo físico, as formas ou ideias precisam também ser informadas ou percebidas em substâncias sensorialmente perceptíveis. Por exemplo, as palavras, ou mesmo os sons em geral, necessitam da materialidade dos corpos físicos e da dinâmica do ar para serem expressos neste mundo.

Os processos e os produtos de informação, organização e integração, entretanto, são primeiramente planejados como conjuntos de ideias ou formas, caracterizando a parte mental das atividades de Design. Por isso, 
"forma" é o principal objeto de estudo de Design. De modo geral, com maior ou menor frequência e eficiência, a capacidade de planejar ações e projetar artefatos é comum aos seres humanos. Mas, como foi anteriormente proposto, o desafio é informar a matéria ou outra substância física configurando os artefatos ou realizando ações, como atuações dos corpos físicos. Assim, as funções distintivas dos designers são: identificar, selecionar e organizar os recursos teóricos, técnicos e tecnológicos para, eficientemente, informar os materiais ou as substâncias físicas, como produtos, instrumentos ou agentes tecnológicos, articulando seu uso ou atuação de maneira integrada com usuários ou outros agentes.

A atividade mentalmente criativa e fisicamente informativa ou configurativa dos designers é confirmada por Löbach (2001), considerando-se que o processo de materialização de uma ideia resulta em informação. Para Bürdek (2005), a atividade de Design é constituída como um processo criativo, cujo desenvolvimento é determinado por condições e decisões que influenciam a configuração do produto. Isso orientou o desenvolvimento da teoria e da metodologia de Design, visando atender o propósito da atividade, que é otimizar métodos, regras e critérios lógicos de projetação.

Tradicionalmente, as atividades de Design priorizam o desenvolvimento ou a melhoria das condições sociais ou morais, de acordo com os valores do contexto de atuação, portanto, partem de um princípio ético. Para Löbach (2001), o projeto de Design registra a busca e propõe solução para um determinado problema. Para tanto, recorre-se ao uso de linguagem específica que, tradicionalmente, inclui croquis, amostras e modelos físicos. Essas informações permitem a percepção sensorial, comunicando ideias para pessoas ou agentes tecnológicos.

Atualmente, os projetos gráficos de comunicação digital são geralmente idênticos aos produtos, sendo que o desenvolvimento do projeto coincide com a própria fabricação do produto. Além disso, de maneira automática e instantânea, o produto gráfico-digital de comunicação é replicável e transmissível na rede Internet, entre outras. Mas, historicamente, o projeto dos produtos em geral são gráficos de diferentes escalas, com indicações numéricas de dimensões e com a configuração geométrica das partes do produto. As informações do projeto orientam a construção de modelos físicos e a fabricação seriada de produtos idênticos. Por isso, Perassi (2015) assinala que, tradicionalmente, a necessidade que definiu a aplicação matemático-geométrica em projetos e protótipos distinguiu a atividade de Design. Tal distinção é especialmente observada com relação à parte da produção poético-artística que, incorporando processos intuitivos de tentativa e erro, foi dedicada à criação de obras únicas.

No percurso histórico, especialmente no contexto de Artes Visuais, houve movimentos cujos artistas investiram na razão lógica e na aplicação de recursos matemático-geométricos na composição de obras. Mas, também, foram recorrentes os movimentos nos quais as obras foram produzidas unicamente com o uso de sensorialidade, intuição e processos de tentativa e erro. Por exemplo, no período renascentista, os artistas norte-europeus 
foram considerados intuitivo-sensualistas e os artistas italianos atuantes em Florença, Milão e Roma, como Leonardo da Vinci, foram considerados lógico-racionalistas (PERASSI, 2005).

A partir do século XIX, as atividades de Design mostraram-se herdeiras das tendências artísticas lógico-racionalistas. Em Arte, a aplicação dos conhecimentos científicos, especialmente os matemáticos, promoveu tecnologias para a produção artística. Mas, em si mesmas, as obras de arte não são recursos tecnológicos. Isso estabelece uma evidente diferença com relação aos projetos de Design, cujas atividades são inseridas no campo tecnológico porque decorrem da aplicação de conhecimentos científicos e também propõem projetos, como recursos tecnológicos para replicação de modelos e fabricação de produtos, participando por isso do campo de Ciências Sociais Aplicadas (PERASSI, 2015).

\section{Design de identidade gráfico-visual de marca}

Na história da produção humana, anterior à época da Revolução Industrial, a área de Design Gráfico é destacada, porque os processos rudimentares de impressão em série são anteriores às técnicas mecânicas de replicação de outros produtos. Por sua vez, a prática de marcação de bens e produtos, por parte de proprietários e fabricantes, também é muito antiga, sendo reconhecida em produtos egípcios e gregos com datação milenar. Atualmente, é designada como Branding a área que trata dos processos de criação, desenvolvimento e gestão de marcas institucionais e comerciais.

Há grandes corporações no mercado global da atualidade que, além de uma marca geral corporativa, também, são proprietárias de diversas outras marcas de instituições, empresas, serviços e produtos. Mas, cada uma das marcas é expressa por um amplo conjunto de produtos de comunicação que podem cumprir outras funções, além da função informativo-comunicativa. Por exemplo, além de informar e participar da comunicação, expressando o nome, as cores e outros símbolos marcantes, as embalagens dos produtos servem funcionalmente para protegê-los, facilitando ainda seu acondicionamento e transporte.

De modo geral, os símbolos gráficos marcantes aparecem em suportes como: veículos, uniformes, embalagens ou outros bens ou produtos associados à marca. Além disso, as características específicas de uniformes e embalagens podem ser publicamente apresentadas e percebidas como símbolos marcantes de uma organização, serviço ou produto. Assim, a identidade visual de marca pode ser composta por múltiplos elementos e aspectos.

Contudo, o sistema gráfico-visual de identidade de marca, tradicionalmente, é composto por: nome da marca desenhado de maneira particular, chamado de "logotipo"; opcionalmente, um símbolo gráfico, que acompanha o logotipo na configuração da assinatura visual; cor ou cores específicas; tipografia oficial; e outros elementos gráficos opcionais, 
incluindo grafismos, mascotes, e outros. Resumindo, Strunck (2012) considera que se trata de um sistema de elementos gráficos que formalizam a identidade visual de marca.

O sistema de identidade gráfico-visual de marca é parte do amplo conjunto de elementos e aspectos de identidade de marca e do programa geral de Branding. Os componentes do sistema, como produtos gráficos de comunicação, são contemplados no conceito da instituição American Marketing Association (AMA apud KOTLER; KELLER, 2012, p. 258), propondo que marca "é um nome, termo, sinal, símbolo, design, ou conjunto desses elementos, que tem como função identificar e diferenciar a oferta de um fornecedor".

A marca central do sistema simbólico de identificação é o nome da instituição, empresa, serviço ou produto. Mas, há outros símbolos marcantes porque são associados ao nome de maneira recorrente e consistente. Por exemplo, o conjunto composto pela cor vermelha e a tonalidade branca é comumente associado ao nome Coca-Cola, passando a representar o negócio e tudo que lhe é associado. Depois que, de maneira recorrente e consistente, uma marca (nome, símbolo figurativo ou cor) foi associada a uma entidade, essa passa a identifica-la, distingui-la e representá-la.

Além de representar uma organização, um serviço ou um produto, os símbolos marcantes também representam as coisas, os sentimentos e as ideias que, anteriormente, foram publicamente associadas à entidade representada. De maneira geral, as pessoas que já tiveram contato com expressões da marca guardam memórias de sensações, sentimentos e ideias associadas ao nome da marca.

Os conceitos de imagem da marca e identidade da marca possibilitam a proposição de objetivos e o planejamento das atividades de gestão da marca. Para Kapferer (2008), a identidade da marca é cultivada pelo público interno e gerenciada pelos gestores da organização, como os principais responsáveis e emissores da marca. Desenvolver e gerenciar a identidade da marca propõe um posicionamento conceitual e social para ser comunicado e cultivado interna e externamente. Isso propicia o planejamento de estratégias e ações de desenvolvimento coerente da imagem e da reputação pública da marca, destacando-as de modo positivo e diferenciado com relação à concorrência.

O sistema de identidade gráfico-visual representa sinteticamente todo o acervo simbólico-cultural que caracteriza a identidade da marca. Tradicionalmente, depois do nome de uma marca, o sistema de identidade gráfico-visual reúne os principais símbolos de identificação, distinção e representação dos valores da marca. Por isso, representa sinteticamente a identidade da marca para o público interno e, também, a imagem da marca para o público externo. $O$ controle eficiente e positivo do desenvolvimento da identidade e da imagem da marca é o desafio central da gestão da marca.

A área de Branding, que abriga os estudos e atividades de gestão da marca, é interdisciplinar, envolvendo conhecimentos e recursos de Marketing, Publicidade e Design. Para Strunck (2012), Marketing é a área responsável por gerir a marca, Publicidade é a área que comunica valores e vende 
a marca, e cabe à área de Design o projeto do sistema gráfico-visual de identidade da marca, além da projetação dos aspectos e elementos funcionais, estéticos e simbólicos de todos os produtos de uso ou comunicação da marca.

\section{A metodologia projetual e os aspectos artísticos em Design}

Há diversas metodologias cujo foco de interesse recai sobre as atividades de Design. Geralmente, essas descrevem, justificam e propõem métodos destinados ao desenvolvimento de projetos de Design. Os diversos métodos de projetação em Design guardam muitas semelhanças entre si. Mas, também são diferenciados uns dos outros, havendo diferenças circunstanciais ou sutis, especialmente no detalhamento dos procedimentos, há ainda outras diferenciações que são mais profundas ou estruturais.

Tradicionalmente, os métodos projetuais de Design costumam ser adaptados para o desenvolvimento de diferentes tipos de projeto. Isso é confirmado por Cameira (2013) que, depois de estudar diversas metodologias, assinalou que as destinadas aos projetos de sistemas de identidade gráfico-visual da marca, em essência, não diferem muito de outras metodologias mais gerais.

As diversas metodologias de projetos de Design preveem: (1) uma parte exploratória de estudos sobre o contexto de proposição do projeto e sobre o problema ou a oportunidade que requer e justifica a atividade de Design e duas partes sintéticas, que selecionam informações e recursos e os aplicam no desenvolvimento do projeto, como a síntese decorrente do estudo e do trabalho realizado. As partes sintéticas são a (2) criativa, de proposição e seleção de alternativas, e a (3) executiva, de realização da alternativa selecionada.

Nas representações gráficas dos projetos de Design em geral, sejam de produtos de uso ou de comunicação, são considerados basicamente três tipos de desenho: (1) desenho livre; (2) desenho técnico, e (3) desenho ilustrativo de apresentação. Esses três diferentes tipos de desenho demarcam a estrutura das partes sintéticas do projeto, sendo que: (1) a parte criativa é caracterizada por desenhos livres; (2) a parte executiva é especialmente definida pelo desenho técnico-geométrico, que indica os formatos e as dimensões de fabricação do produto; também, é comum a execução de diferentes soluções de prototipagem ou (3) a realização de desenhos ilustrativos de apresentação, com o uso de técnicas de ilustração, como a renderização (Figura 1).

As imagens a seguir representam os três tipos de desenho que, tradicionalmente, embasam as partes sintéticas, criativa e executiva, dos projetos de Design. A organização e as características dos elementos componentes das imagens sugerem o projeto gráfico de um produto de comunicação, como uma marca visual de características estético-simbólicas específicas. Todavia, o mesmo conjunto de imagens também sugere a produção manual ou artesanal dos desenhos. Isso deve ser especialmente considerado na 
Fig 1. Desenhos de registro e representação do projeto: (1) desenho livre; (2) técnico; (3) ilustrativo Fonte: Infográfico produzido pelos autores
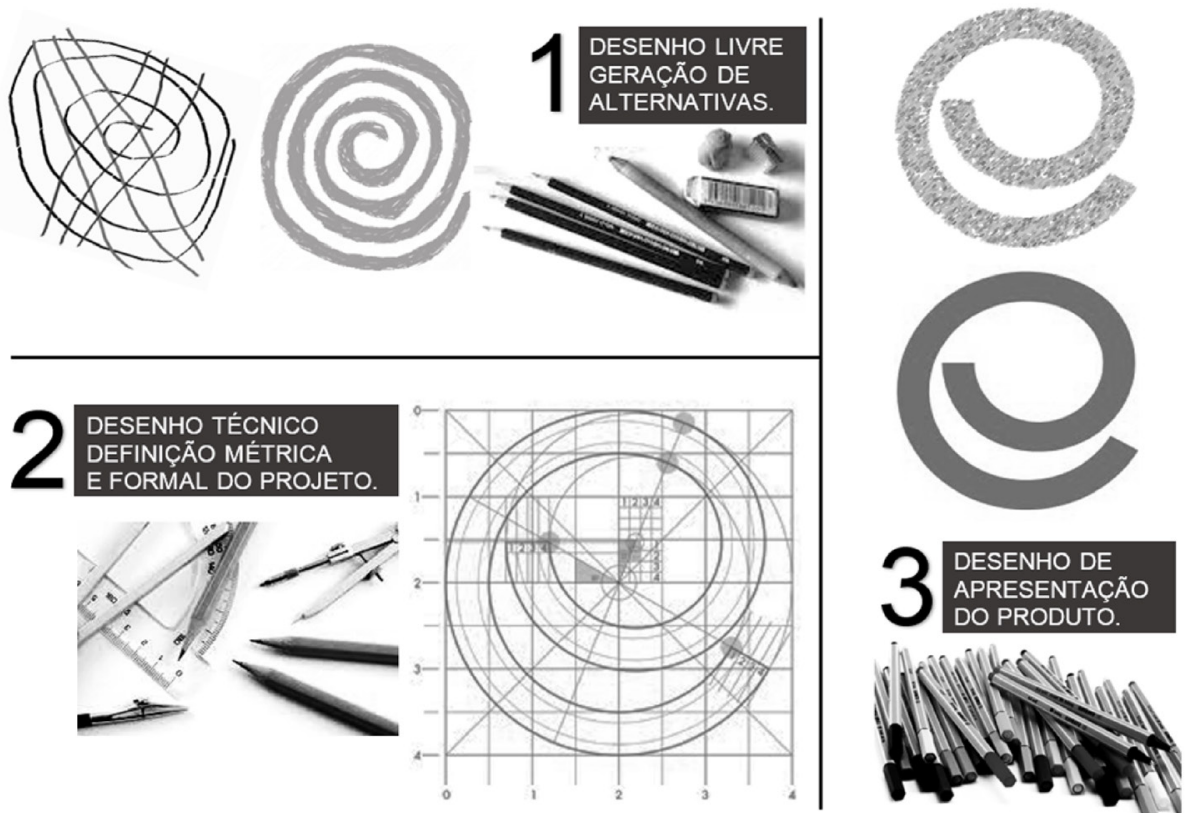

parte da construção geométrica, que descreve o processo de construção, a proporcionalidade entre as dimensões e o formato do desenho, permitindo sua proposição como modelo passível de ser replicável.

Antes da possibilidade de acesso aos sistemas eletrônico-digitais de computação gráfica, a adequação e a representação geométrico-manual ou artesanal da alternativa selecionada caracterizavam o problema e a atividade central da parte executiva e, também, de todo o processo de projetação. Isso era justificado pelo fato de que, depois da representação geométrico-descritiva, o projeto gráfico passava a ser o modelo que permitia a replicação do produto em diferentes escalas.

Depois do advento dos recursos de computação gráfica, as práticas artesanais de desenho passaram a ser opcionais. As imagens digitalizadas, depois de terem sido artesanalmente produzidas, assim como os desenhos realizados no próprio sistema gráfico-digital, de maneira automática e imediata, são reconhecidas e registradas como arranjos matemático-geométricos. $\mathrm{Na}$ computação gráfica, há como optar pelo registro automático da imagem como composição vetorizada e, entre outras possibilidades, isso permite sua ampliação ou redução sem deformação, porque é mantida a proporcionalidade entre as dimensões de seus elementos.

Diante dos avanços tecnológicos descritos, as etapas de síntese criativo-executiva dos projetos de Design Gráfico em geral, e dos projetos de sistemas de identidade gráfico-visual de marcas em particular, foi radicalmente transformada. Independente da maneira como cada designer realiza seus projetos, desde que esses sejam realizados com recursos tecnológico- 
-digitais eficientes, é possível garantir a qualidade especificamente técnica de reprodução dos produtos gráficos, mesmo que tenham sido desenvolvidos por processos intuitivos de tentativa e erro.

Mantida a qualidade técnica do sistema digital, também, ocorre a plena identidade entre o projeto e o produto gráfico. Os desenhos realizados no sistema digital são automaticamente replicáveis e transmissíveis a outros sistemas digitais. Inclusive, também são digitalmente transmitidos para serem materialmente impressos em diferentes suportes. Há impressoras que percebem os sinais digitais e realizam o trabalho mecânico de impressão, reproduzindo com tinta os valores tonais e cromáticos das imagens percebidas nas telas de vídeo.

Diante da realidade atual, a tradicional prioridade dos designers pelo domínio dos recursos de Desenho de Observação e Desenho Geométrico ou por conceitos de Teoria da Forma e Composição Visual foi substituída pela busca por conhecimentos atualizados e pelo domínio dos recursos tecnológico-digitais. Além disso, o reconhecimento de aspectos sociais, mercadológicos e tecnológicos predominantes ou influentes no contexto de realização do projeto assumiu maior relevância que os aspectos formais da representação gráfico-projetiva. Atualmente, foi incorporado pelo sistema tecnológico-digital e também superado o que, anteriormente, era o principal desafio técnico dos designers, os quais deviam saber representar com precisão matemático-geométrica uma forma ou ideia.

Entretanto, independente das circunstancias anteriores ou atuais, na parte criativa do projeto de Design, escapa-se da formalidade metódica e tecnológica, enfatizando-se a intuição, o senso estético e o processo de tentativa e erro. O procedimento metodológico geralmente recomendado é a prévia composição de painéis semânticos (Figura 2) ou mood boards. Contudo, apesar de ser uma prática consolidada e com múltiplos exemplos para visualização, não há regras lógicas ou específicas para a seleção e a organização de imagens, figuras, cores e texturas em painéis semânticos ou mood boards.

Intuitivamente, o designer experimenta e seleciona subjetivamente sensações, sentimentos e ideias, as quais são sentidas como coerentemente relacionadas com o contexto do projeto. De posse desse repertório subjetivo, o designer pesquisa imagens que, pelo menos aproximadamente, expressam sensações, sentimentos e ideias semelhantes as que foram subjetivamente vivenciadas. Assim, seleciona um repertório visual, externo e objetivo, de imagens interessantes. Por fim, também intuitivamente, o designer organiza as imagens selecionadas em painéis de apresentação, reunindo figuras, cores e texturas que, previamente, foram consideradas estética e simbolicamente interessantes.

Além disso, no campo de Design Gráfico em geral, incluindo os projetos de criação de sistemas de identidade gráfico-visual, não há critérios lógicos para a definição da solução mais apropriada, especialmente, com relação às variações estéticas. Por exemplo, pode-se considerar que os valores centrais que caracterizam a identidade de determinado negócio são positivamente expressos por figuras aladas. Em seguida, buscando-se uma figura 

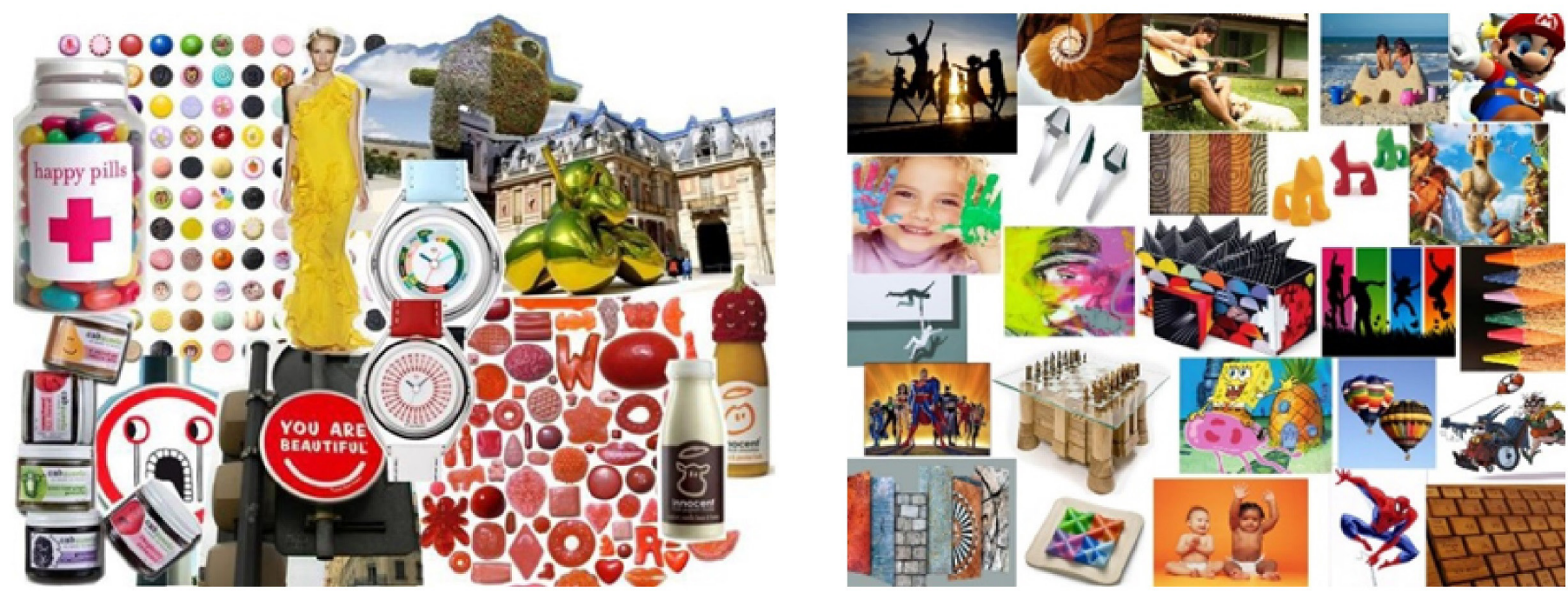

Fig 2. Imagens de painéis semânticos com sugestões de figuras, cores, tonalidades e texturas

Fonte Ibubuiaacessorios.blogspot.com. br e lucasnegaouol.blogspot.com.br
Fig 3. Representações de pares de asas com mesmo estilo gráfico e desenhos diferentes.

Fonte: freepik.com/fotos-vetores-gratis/asas objetiva, sintética, e coerente com a identidade do negócio, é proposto que o desenho da marca deve representar um par de asas. Considera-se ainda que, esteticamente, o desenho deve ser sóbrio, monocromático, ordenado e clássico, porque são esses os atributos do negócio representado pela marca.

De maneira geral, as proposições e as considerações semelhantes às apresentadas no parágrafo anterior não decorrem de princípios lógico-quantitativos, porque são tipicamente analógicas, qualitativas e estético-intuitivas, resultando de impressões subjetivas ou intersubjetivas, que foram consideradas coerentes com as características estético-simbólicas do negócio. Portanto, essas características estético-simbólicas também devem ser expressas no desenho da marca. Mas, sempre haverá várias possibilidades estéticas diferentes e coerentes, mesmo que sejam rigorosamente atendidos os critérios previstos, com desenhos monocromáticos de um par de asas em estilo sóbrio, ordenado e clássico (Figura 3).

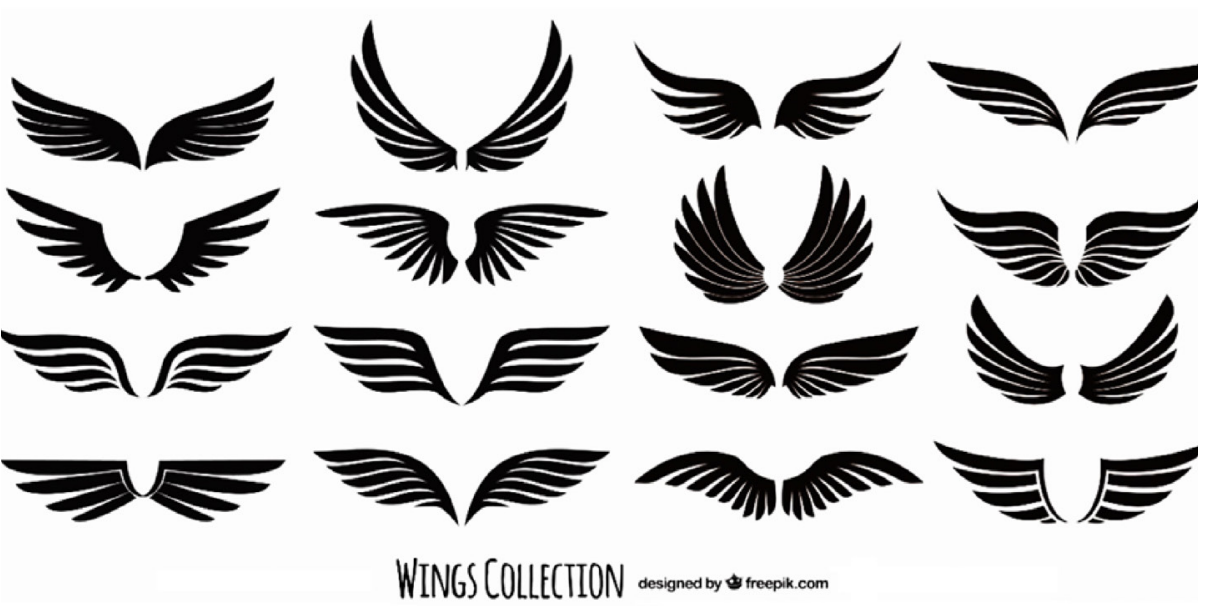

DATJournal v. 5 n. 12020 
Em síntese, de impressões subjetivas e estético-intuitivas do próprio designer ou de impressões intersubjetivas, resultantes de consultas a outros interessados ou a pessoas em geral, podem ser desenvolvidas e propostas diversas alternativas gráficas que, sendo parcialmente diferentes, ainda atendem individualmente os critérios do projeto.

Um artista pode desenvolver uma coleção de desenhos únicos sobre uma mesma temática, usando uma mesma técnica e recorrendo a um mesmo estilo. Um designer também pode oferecer aos gestores da marca uma coleção de símbolos visuais em que a temática, a técnica e o estilo gráfico atendam ao que foi previsto para o projeto.

Geralmente, ocorre uma pré-seleção feita pelo próprio designer, reduzindo as opções que são apresentadas aos gestores da marca. Uma alternativa é a apresentação dos critérios e dos símbolos gráficos a pessoas cujo perfil é de clientes ou consumidores da marca, para que haja avaliações e seleções por parte do público interessado. Isso pode ser realizado antes ou depois de uma primeira apresentação dos resultados aos gestores da marca, que também são os clientes do projeto.

Em resumo, os processos de reconhecimento dos valores da identidade da marca e da escolha da alternativa gráfica de identificação podem ser realizados de maneira individual, pelo designer, ou coletiva, envolvendo outros participantes. Todavia, em qualquer situação, esses processos são desenvolvidos e resolvidos predominantemente por avaliações qualitativas, analógicas e estético-intuitivas, que escapam dos parâmetros métricos e de decisões lógicas ou formais. Tais processos podem ser organizados e hierarquizados com relação à sequência de procedimentos. Também, quando envolvem as indicações de muitas pessoas, é possível justificar quantitativamente que uma alternativa gráfica foi mais indicada do que as outras. Mas, isso não altera o caráter intrinsecamente estético-intuitivo, subjetivo ou intersubjetivo desses processos qualitativos. 


\section{Considerações finais}

Atualmente, vive-se um tempo marcado pela diversidade, sendo o processo continuado de diversificação tão amplo, dinâmico e variado que dificulta e desconsidera os esforços de organização ou categorização do conhecimento. Historicamente, sempre houve a constante intersecção das áreas de Arte, Ciência, Técnica e Tecnologia. Além disso, há áreas de estudos e atividades cuja origem, desenvolvimento e produção foram estabelecidos na constante interação entre teoria e prática, lógica e intuição, sensibilidade e cognição ou cálculo.

As áreas de Ciências Aplicadas são exemplos disso, porque aplicam o conhecimento teórico-científico nas funções prático-factuais, visando à criação e a proposição de recursos, conceituais ou materiais, para serem usados no cotidiano da vida humana e social. Os recursos conceituais, decorrentes da formulação teórica e sistemática de fórmulas, métodos ou dinâmicas e, também, os recursos materiais, como instrumentos, ferramentas e sistemas mecânicos ou eletrônicos, entre outros, são os recursos tecnológicos. Portanto, a denominação "tecnológica" é justificada, porque os recursos desenvolvidos para a atuação prática resultaram da aplicação obrigatória, recorrente e sistemática dos conhecimentos teórico-científicos.

As áreas e as atividades que compõem o sistema designado como Design são consideradas no contexto acadêmico de Ciências Sociais Aplicadas. São áreas que aplicam de maneira recorrente e sistemática o conhecimento teórico-científico na produção de recursos, em formato de projeto, para a produção e a reprodução de outros recursos úteis para a vida humana e social.

Neste artigo, procurou-se identificar e apresentar quais os recursos teórico-científicos que, tradicionalmente e continuamente, foram aplicados em estudos e atividades de Design, caracterizando suas áreas no contexto tecnológico. Assim, indicou-se os conhecimentos matemático-geométricos como sendo os tradicionalmente mais característicos da aplicação da teoria científica nas áreas de Design.

Anteriormente, para atuar nas áreas de Design era imprescindível o domínio teórico-prático de conhecimentos de Matemática e, especialmente, Geometria. Isso foi justificado porque a fabricação e a replicação de modelos e produtos dependiam e ainda dependem de referências métricas e geométricas em escalas precisas. Contudo, atualmente, no contexto da tecnologia eletrônico-digital, os programas de computação gráfica realizam o registro automático e imediato das relações métricas e geométricas dos projetos gráfico-digitais. $\mathrm{Na}$ área de Design Gráfico e, especialmente, nos projetos de criação de elementos gráfico-visuais de identidade de marca, isso provocou mudanças radicais. Por exemplo, depois de digitalizar e "vetorizar" de maneira competente uma imagem, obtêm-se de imediato um modelo idêntico ao produto, o qual pode ser ampliado ou reduzido e aplicado com qualidade técnica. 
Diante do exposto, designers e outros interessados na produção e na reprodução de imagens gráficas conquistaram ampla liberdade criativa. Práticas e produtos que, tradicionalmente, eram considerados mais poéticos ou artísticos, puderam ser plenamente adotados por designers. De maneira semelhante, outras práticas e produtos que, tradicionalmente, eram considerados mais tecnológicos e próximos dos designers puderam também ser plenamente adotados por artesãos e artistas.

Recuperando o exemplo das representações gráficas de um par de asas, destaca-se que, anteriormente, o planejamento, a construção e a descrição geométrica da representação de cada um dos 16 desenhos de par de asas (Figura 3) requeriam sólido conhecimento de geometria aplicada e habilidade no manuseio dos instrumentos de desenho técnico. O domínio da tecnologia de desenho manual era diretamente relacionado com a capacidade artística e técnico-científica ou tecnológica do próprio designer. Atualmente, desde que o designer ou outro usuário domine os recursos gráfico-digitais, com processos rápidos de tentativa e erro, é possível realizar mais facilmente o desenho de figuras complexas, obtendo-se bom acabamento técnico e, de imediato, o registro matemático-geométrico do desenho realizado.

Situações como as descritas anteriormente reforçam a tendência de diversificação da atualidade, propondo diversas possibilidades para artistas ou designers. Isso permite também a identificação entre artistas e designers, facilitando as considerações de que todo designer é um artista e vice-e-versa. Não há aqui a pretensão de fixar uma percepção única ou categórica, mesmo porque isso parece ser anacrônico ou intempestivo na atualidade. Neste artigo, entretanto, procurou-se caracterizar o domínio poético, estético-intuitivo ou artístico, no processo criativo de geração e seleção de alternativas dos métodos projetuais de Design, mais especialmente, nos projetos de Design Gráfico destinados à criação de símbolos gráfico-visuais de identidade de marcas.

Apoio

O presente trabalho foi realizado com apoio da Coordenação de Aperfeiçoamento de Pessoal de Nível Superior - Brasil (CAPES) - Código de Financiamento 001. 


\section{Referências}

BONSIEPE, Gui. Design, cultura e sociedade. São Paulo: Blücher, 2011.

BUNGE, Mario. La ciencia, su método y su filosofía. Buenos Aires: Siglo XXI, 1969.

BÜRDEK, Bernhard E. História, Teoria e Prática do Design de Produtos. São Paulo: Edgard Blücher, 2006.

CAMEIRA, Sandra R. Branding + Design: o branding e a metodologia de sistemas de identidade visual. 2013. 428 f. Dissertação (Mestrado em Arquitetura e Urbanismo) - Faculdade de Arquitetura e Urbanismo, Universidade de São Paulo. São Paulo, 2013.

CUPANI, Alberto. A tecnologia como problema filosófico: Três enfoques. Scientia e Studia, São Paulo, v.2, n.4, 2004. p.493-518.

FLUSSER, Vilem. 0 mundo codificado: por uma filosofia do design e da comunicação. São Paulo: Cosac Naify, 2007.

JAPIASSU, Hilton; MARCONDES, Danilo. Dicionário básico de Filosofia. Rio de Janeiro: Jorge Zahar, 2001.

KAPFERER, J. N. The new strategic brand management: creating and sustaining brand equity long term. London/Philadelphia: Kogan page, 2008.

KOTLER, P.; KELLER, K. L. Administração de Marketing. São Paulo: Pearson Education do Brasil, 2012.

LÖBACH, Bernd. Design industrial: bases para a configuração dos produtos industriais. São Paulo: Blücher, 2001.

LUCIE-SMITH, Eduward. Dicionário de Termos de Arte. Lisboa: Dom Quixote, 1990.

MAIO, F. A encenação da Arte. Lisboa: Textverso, 2011.

PEÓN, Maria Luísa. Sistemas de identidade visual. Rio de Janeiro: 2AB, 2001.

PERASSI, Richard. Sintaxe gráfico-visual no ensino de Design na Universidade. Lisboa: IADE, 2015 (Relatório de estágio pós-doutoral).

PERASSI, Richard. Roteiro da Arte na Produção do Conhecimento. Campo Grande, MS: EDUFMS, 2005.

ROWLEY, J. EDUMUNDSON-BIRD, D. Brand Presence in Digital Space. Journal of Eletronic Commerce in Organizations, v.11, n.1, p. 63-78, 2013. Disponível em:< http://www.igi-global.com/article/brand-presence-digital-space/78557>. Acesso em: 14 ago 2016.

STRUNCK, G. Como criar identidades visuais para marcas de sucesso. Rio de Janeiro: Rio Books, 2012.

VALENTIM, Marta L. P. Métodos qualitativos de pesquisa em ciência da informação. São Paulo. Ed. Polis, 2005. 